\title{
0 contraponto da resiliência em mulheres na clínica
}

\author{
The counterpoint of resilience an women in the clinic
}

\author{
Caren Schultes Borges ${ }^{1}$ e Paulo Fernando Monteiro Ferraz
}

Resumo: Este artigo configura uma releitura de estudo investigativo de referenciais bibliográficos nacionais em Psicologia, de forma não sistemática, com viés narrativo-qualitativo sobre as (im)possibilidades de avaliação da resiliência psicológica em mulheres brasileiras frente ao contexto do mal-estar contemporâneo. Trata-se de um ensaio teórico de abordagem qualitativa a partir de vinhetas clínicas advindas da prática em consultório de Psicologia na capital. Marília, Serena e Anita narram suas histórias, construindo um mosaico acerca da resiliência. Avaliar a força psíquica dessas mulheres, bem como suas fragilidades, frente aos fenômenos psicossociais resultantes da lógica perversa do capitalismo, incita tarefa árdua para psicoterapeutas. Busca-se, através das vinhetas, espelhar possibilidades e impossibilidades de identificar e avaliar a resiliência de mulheres na clínica em contraponto com as novas formas de subjetividades e singularidades naquelas que apresentam traços de personalidade dependente. Objetiva- se, trazer à luz, a necessidade de instrumentalização profissional, para a adoção na prática clínica, de maior diálogo entre abordagens qualitativas e quantitativas na avaliação psicológica da resiliência e o cuidado especial em não reforçar a dependência na relação terapêutica. A resiliência enquanto competência psicológica constitui fator de proteção à saúde psíquica. Pode ser avaliada e promovida na clínica. É o fenômeno a ser mais estudado em Psicologia.

Palavras-chave: Resiliência Psicológica; Mulheres Resilientes; Prática Clínica.

\begin{abstract}
This article configure a reading of the investigative study of national bibliographic references in Psychology, in a non-systematic way, with a narrative- qualitative bias about the (im) possibilities of assessing psychological resilience in women facing contemporary malaise. Is a theoretical essay based in clinical vignettes derived from practice in a psychology office in the capital, Marília, Serena and Anita narrate their stories building a mosaic about resilience. Finding the psychic strength of these women as well as their weaknesses, in the face of the psychosocial phenomena resulting from the perverse logic of capitalism, is an arduous task for any professional. It can be evaluated and promoted in the clinic. Sought with the vignettes to reflect possibilities and impossibilities of new forms of subjectivity and singularity in a women that present dependent personality traits. The objective is to bring to light the need for professional instrumentalization, for adoption in clinical practice, for greater dialogue between qualitative and quantitative approaches in the psychological assessment of resilience an special care in not reinforcing dependence on the therapeutic relationship. Resilience as a psychological competence is a protective factor for mental health. It is a phenomenon to be further studied in Psychology.

Keywords: Psychological Resilience; Female Resilience; Clinical Practice.
\end{abstract}

\footnotetext{
1 Psicóloga. Sócia SPRGS. Terapeuta Familiar Sistêmica. Especialista em Avaliação Psicológica. Mestre em Desenvolvimento Regional (UNISC). E-mail: carensborges.csb14@gmail.com

2 Psicólogo. Psicanalista em formação no CEP. Mestre em Psicologia Social e Institucional (UFRGS).

E-mail: pauloferraz1980@gmail.com
} 


\section{Introdução}

A sociedade democrática exige, cada vez mais, a liberdade de ser e estar. Para as mulheres, não é diferente. 0 individualismo, o narcisismo e o produtivismo, característicos do capitalismo, suscitam desejos de sucesso econômico e de status social. Essas exigências não contribuem para a resiliência do feminino. Tornar-se mulher sem seguir o padrão do capitalismo é um desafio às novas formas de subjetividade. Não se trata de ressaltar um feminismo estressado ou histérico, mas de dar voz à liberdade e à capacidade de mudar o próprio destino. Ir além da liberdade de pensar o que todos pensam (Rouanet, 1993).

Novas formas de subjetividade vêm sendo construídas diante do contexto do mal- estar contemporâneo. Embora, o mal-estar seja inerente a qualquer tipo de civilização, em qualquer estágio evolutivo. Presume-se que ele se revista de formas específicas conforme o período histórico (Rouanet, 1993).

De acordo com Bauman (2004) e Birman (2004), a a lienação aprendidae difundida nas redes sociais e na mídia têm alterado a sensibilidade das pessoas favorecendo o surgimento de valores anticivilizatórios e causadores de sofrimento e adoecimento psíquico reforçando uma fragilidade nos laços sociais.

0 individualismo atual, característico do capitalismo, e desejos de sucesso econômico e status social, não têm contribuído para a resiliência do feminino. De acordo com Christina Berndt (2018), distúrbios psíquicos como ansiedades, depressões e Síndrome de Burnout têm aumentando na população feminina. Segundo esta investigadora de resiliência no cenário da globalização as mulheres vivenciam o sentimento de obrigação de repetir que o que não falta é trabalho e que são muito importantes e têm muito a fazer, esquecendo o fato de que 0 estresse constante é um risco à saúde. As mulheres têm sofrido cada vez mais de patologias do estresse e estão mais vulneráveis às novas adversidades devido a sua maior necessidade de suporte social (Berndt, 2018).

A resiliência é um termo recente na Psicologia, mas tema pertinente e de objetivos já bem conhecidos nesse campo de saber. 0 exercício da autonomia e do autocuidado é um devir natural do ser humano, 0 qual vai sendo moldado pela cultura. As mulheres de hoje parecem sofrer mais do mal-estar contemporâneo: narcisismo, individualismo, status e poder. Ter à ser. As pressões sociais vivenciadas por mulheres têm pesos diferentes em sua constituição como sujeitos de direitos. As oportunidades de acesso à educação e ao trabalho são desiguais para homens e mulheres. Essas têm renda inferior de $28 \%$ em relação aos homens, apesar do nível educacional mais elevado. Ensinar resiliência para as mulheres não está atrelado unicamente ao empoderamento de mulheres afrodescendentes, indígenas, pobres ou oriundas do meio rural, nem àquelas que sofrem violência de gênero. A resiliência é necessária a todas as mulheres e vem ao encontro do fortalecimento da autonomia, da independência, da autoeficácia e da flexibilidade em lidar, de forma menos sensivel, às adversidades. A força psíquica das mulheres está, em grande parte, atrelada à aprendizagem de autonomia e independência. Com os elos fragilizados da Sociedade Líquida (Bauman, 2004), da Sociedade do Espetáculo (Debord, 1967) e da Sociedade do Cansaço (Han, 2017), todas as mulheres estão em risco de adoecimento psíquico. A Psicologia precisa estar articulada às questões sociais e fenomenológicas da atualidade e atenta às versões atualizadas das classificações diagnósticas dos Transtornos Mentais, sob um viés não reducionista e, sim, dialético.

De acordo com o Manual Diagnóstico e Estatístico de Transtornos Mentais (DSM-V) (APA, 2014), no campo da Psiquiatria, o Transtorno de Personalidade Dependente constitui um padrão comportamental persistente que prejudica a qualidade de vida da pessoa. A prevalência é maior em mulheres. As principais características desse padrão comportamental disfuncional compõem uma necessidade generalizada e excessiva de ser cuidada levando à submissão e a uma maior sensibilidade às desaprovações, temendo 0 abandono e a perda de suporte. Além disso, há uma alta exigência de reafirmação e aconselhamento para a tomada de decisões comuns. São pessoas que experimentam uma alta ansiedade 0 enfraquecimento da autonomia. 0 tratamento inclui psicoterapia e possivelmente, antidepressivos. A resiliência em mulheres como contraponto da personalidade dependente - pode ser investigada e promovida com mais assiduidade nos atendimentos. A avaliação psicológica da resiliência pode ser feita de forma qualitativa e quantitativa, em articulaçãa. 0 pluralismo metodológico tenderia a ser mais integrativo. No Brasil, grande parte dos psicólogos não utiliza testes em sua prática clínica.

É premente conhecer o conceito de resiliência e as possibilidades de avaliá-la em mulheres adultas diante do sofrimento psíquico, subjacente ao contexto dos fenômenos psicossociais contemporâneos.

0 estudo supracitado acerca das (im)possibilidades de avaliação da resiliência psicológica em mulheres brasileiras no contexto do mal-estar contemporâneo apontou o uso de escalas como principais instrumentos de avaliação da resiliência em Psicologia. As escalas de resiliência RSA e CD-RISC foram os instrumentos mais adotados e estudados para avaliar o construto da resiliência, mesmo não estando favoráveis pelo Sistema de Avaliação de Testes Psicológicos - SATEPSI. Respectivamente, a Escala de Resiliência em Adultos - RSA, desenvolvida por Wagnild e Young (1993) e a Escala de Resiliência de Connor e Davidson - CD-RISC (ERA). Outro instrumento foi referenciado e está disponível pela Vetor Editora: A Escala de Pilares da Resiliência - EPR. No entanto, ela também não consta na lista do Satepsi. A utilização de testes psicométricos validados deveria ser um recurso mais vantajoso para pesquisadores da área, pois auxiliam na identificação de riscos e apontam expoentes de prevenção, assim como intervenções (Reppold, 2012).

Para Yunes e Symanski (2001) a resiliência é um termo interdisciplinar, dinâmico e relacionado à Psicologia Positiva. Apresenta dissenso conceitual e está associada ao enfrentamento do estresse, de patologias específicas ou de fenômenos psicossociais entremeados à saúde e ao trabalho. Resiliência, em avaliação psicológica, está correlacionada a fatores de risco e de proteção. As principais vertentes de adoecimento psíquico para mulheres são: estresse, ansiedade e depressão. Patologias do estresse, a exemplo da síndrome de Burnout, têm acometido um grande número de mulheres, que se tornam reféns de um modelo perverso e positivista que tende a exaltar o trabalho e a saturar a rotina de todos (Berndt, 2018).

Para Yunes (2003) o suporte social é considerado o principal fator de proteção. Experimentar de forma saudável reduz os efeitos maléficos do estresse. As mulheres, em geral, necessitam de apoio emocional básico no quesito "sobrevivência". Evoluem mais em ambientes sociais e complexos. Família, amizades e casamento têm papel protetor fundamental na resiliência do feminino. No entanto, são mais vul neráveis ao sofrimento psíquico quando os estressores são justamente oriundos dessas relações. Nesse universo da resiliência, 0 consultório se faz locus de histórias de vidas que espelham as múltiplas particularidades da força psíquica feminina. Esse ensaio desvela, através de vinhetas de casos clínicos, as diversas facetas da resiliência em mulheres contemporâneas e corrobora - enquanto viés qualitativo para avaliação, intervenção e prevenção do sofrimento psíquico - a premissa de que o olhar e as escutas exercem papéis essenciais à prática clínica. 


\section{Marília - não é Amélia, mas também é mulher de verdade?}

Marília era uma mulher madura a caminho dos 60 anos. Buscou terapia não pela aposentadoria, mas quando o ninho começou a ficar vazio. 0 casamento de 40 anos perdeu a vitalidade e transformou-se em amizade. Vivem, hoje, vidas paralelas. Ele retornou ao lar materno, na mesma quadra. Seguem juntos 0 empreendimento de van- escolar e a provisão aos filhos adultos. Marília viu-se abalada quando a filha caçula anunciou formatura e casamento. Uma relação de dependência emergiu. Marília que era professora na rede pública viu sua rotina mudar. 0 horário das aulas que ministrava nos turnos tarde e noite deram espaço para um tempo com a filha em casa. Acompanhava seus estudos de anos finais de estágio e longas conversas de aconselhamento sobre o noivado. Durante as manhãs, cuidava do neto e auxiliava nas vans. Sua vida social estava reduzida às relações familiares. As crises de ansiedade e depressão despontaram. Marília apresentou sintomas no corpo: diverticulite e aumento da pressão ocular. Entre tratamentos ambulatoriais e cirúrgicos, Marília alternava as crises. Um ato aparente da necessidade de ser cuidada. A cada diálogo de possibilidade de autonomia da filha, Marília recaía. Parou de dirigir e exigia acompanhamento da filha às consultas médicas. Entrou em depressão.

0 tratamento combinado foi sugerido e adotado. A psicoterapia continua útil e incorporada à rotina. Ela foi diagnosticada com traços de personalidade dependente. Uma realidade da condição feminina nos consultórios. 0 trabalho psicoterápico demanda sensibilidade e uma aguçada capacidade de vinculação. A adesão ao processo psicoterapêutico reside aí. Entretanto, a prevalência de personalidade dependente em mulheres é elevada (APA, 2014). É importante ter cuidado.

Na situação acima, é notória a falta de uma rede social de apoio para além do núcleo familiar. A depressão e a ansiedade tiveram raízes nas angústias de separação e nos medos subjacentes à rejeição e ao desamparo social. A vinheta denuncia a vida de uma mulher aprisionada ao desempenho de papéis cristalizados em torno da função materna e dos expedientes do casamento. A ontogênese de Marília transcorreu desassociada dos circuitos de autonomia e de independência. Foi assim que formou sua personalidade. Vivemos em uma sociedade que (im)possibilita uma educação de liberdade de escolha às mulheres? Quantas Marílias chegam até nós sem nunca terem se questionado sobre a repercussão das escolhas e os propósitos de vida? A resiliência poderia ser transmitida nas escolas (e por que não?) e nos programas de políticas públicas de saúde da mulher. Ensinar competências emocionais, impelir a coragem de romper com modelos impostos pela sociedade, sair do papel masoquista de ser vítima do próprio destino ainda são desafios hercúleos (Shainess, 1984). Os caminhos para testemunhar a resiliência na clínica perpassam o campo onírico dos terapeutas. Diante dessa "premissa", nasceu o caso Serena.

\section{Serena - toda mulher é meio Leila Diniz?}

Serena é uma pessoa ousada que aceita a condição de ter nascido mulher. Não se percebe invencível e não leva tudo tão a sério. Sorri alto, sem medo de ser julgada, tem uma gargalhada gostosa. Ri de si mesma quando erra. Onde passa, deixa sua marca de positividade. Tem fé no sentido da vida. Não fica esquecida. Pessoa leve, feito brisa de verão. Apresenta humor regulado. Enfrenta suas "TPMs" com resiliência. Faz leituras de atualização sobre mulheres maduras e resolve dias difíceis com duas drágeas e cacau meio amargo. Ou pede ajuda aos especialistas. A enxaqueca vence com tapa-olhos e quarto escuro ao dormir. Os lençóis têm cheiro de lavanda.

Aprendeu a curtir momentos em silêncio. A agenda é digital, mas também usa 0 diário. Sua escrita é sincera, entre realista e otimista. Administra 0 tempo com a maestria de quem pesquisou em livros, e no Google a higiene do sono e a qualidade de vida em Veranópolis. Acredita-se mulher equilibrista de seu tempo. 0 trabalho remunerado não consome sua motivação diária. Sente-se pertencente à equipe de trabalho. Entende que não são sua nova família nem as melhores amigas. Colegas são colegas, contribuem juntos para o progresso da empresa.

Conhece bem seu propósito de vida, que tem um quê de transcendente. 0 trabalho em casa faz quando pode. Não se escraviza. E, quando precisa, pede ou contrata ajuda da Cida ou da Ritinha. São ajudantes. 0 restante das tarefas domésticas compartilha com o parceiro. Já cortou a grama enquanto ele lavou e guardou as roupas. Divertem-se, não competem! Esporadicamente, negociam e conversam as regras da vida a dois. Não esperam a crise dos 7 anos se instaurar.

Serena exercita-se com frequência e adotou a dieta mediterrânea. Agenda café e cinema com as amigas, sem culpa. Vez ou outra, vai sozinha ao cinema. Gosta da própria companhia. Crê na solitude. Delega a tarefa de buscar o filho caçula na escola para a vizinha amiga. No happy hour com as amigas, conversa sobre tudo, inclusive os sonhos e planejamentos em torno de viagens. Só evita as tradicionais queixas de marido, filhos e desfecho de novelas. Nena, como é carinhosamente apelidada, construiu amizade especial com Carlinda, quem considera sua amiga confidente. Mesmo que a maioria de seus dilemas desaguem no divã, conta com o apoio de Carlinda.

Em férias, descobriu que um mês inteiro é essencial. Équando "despluga" e desopila. Relaxa com os fragores da natureza. Não leva parentes: os encontra apenas em aniversários e natais. Étempo de renovação e descobertas. Participa da família de origem dando suporte e apoio emocional básico, sempre que possível. Diante de pedidos abusivos, permite-se dizer não. Faz concessões e sacrifícios, mas também celebra e vibra com o progresso de toda sua gente. Nem sempre medita, porém ouve música com frequência. Ao sol, lê poesia. Quando tensa, agenda salão de beleza e massagem. Cuida- se, sem culpa. Gasta consigo, não com presentes caros para impressionar os amigos. Tem empatia, presenteia ao gosto deles. Não catequisa, nem dá moral em cartões de natal. É pessoa leve, feito brisa de outono.

\footnotetext{
3 A frase "não é Amélia, mas também é mulher de verdade" faz referência à música "Ai que saudade da Amélia", composta por Mário Lago e Ataulfo Alves, em 1942. A música é considerada um clássico do samba e obra-prima pelo historiador da música brasileira Jairo Severiano. "Amélia" tornou-se conceito no Dicionário Aurélio: "Mulher que aceita toda sorte de privações e/ou vexames sem reclamar, por amor a seu homem".

4 A frase "toda mulher é meio Leila Diniz" faz alusão a um trecho da música "Todas as Mulheres do Mundo", da cantora Rita Lee. E, também, ao livro e à tese de doutorado, sob o mesmo título, da autora Mirian Goldenberg. O termo focaliza a libertação feminina. Conforme a Wikipédia, Leila Diniz, defensora do amor livre e do prazer sexual, quebrou tabus de uma época em que a repressão dominava o Brasil ao exibir sua gravidez de biquíni em praia carioca. É sempre lembrada como símbolo da revolução feminina.
} 
Ao passear por jardins, observa e cheira o perfume das flores. Encanta-se com os pássaros. Mira o céu e o horizonte. Assiste as nuvens passarem bem devagar. Contempla o crepúsculo. Em casa, montou uma pequena horta. Ali plantou alguns temperos: manjericão, alecrim, hortelã e sálvia. Tem orgulho de seus verdes. Rega sempre que bebe um copo d'água na cozinha.

Gosta de dirigir sem pressa, diz-se prudente. Não gosta de atalhos, segue caminhos seguros e iluminados. Conversa com outros homens, de forma assertiva. Sua vaidade se coaduna com o próprio bem-estar. Não precisa sentir-se desejável o tempo todo. Ama-se como está. Gosta de pisar na grama e mergulhar no mar. Não tem aversão à areia e nem aos pelos de bichos. Abraça e afaga os cães. Acaricia os cabelos dos filhos. Às vezes, dança na sala. Beija 0 marido. Abraça o pai. Faz uma longa ligação para a mãe. Escreve cartas às amigas. Tem dias de unhas e cabelos mal feitos. Gosta de experimentar a liberdade. Foi mãe porque quis, não por pressão social. Quando o filho mais velho cresceu, deixou ir. Ensinou-lhe autonomia. Passou em revista a vida. É mulher livre, nem sempre madura. Aprende e melhora com os equívocos. Aliás, fez as pazes com as autocríticas. É perspicaz diante do novo. E, quando não sabe, pede ajuda. Críticas não a destroem. Ouve e chora, depois se recompõe. Enfrenta e aprende. Aprendiz da vida que é, cresceu com amor. Venceu 0 desafio de nascer mulher e conquistou um lugar no mundo. É pessoa serena.

Serena chega ao consultório vulnerável. Uma pandemia no mundo a fragilizou? Não saberíamos a resposta. Relatou a viuvez recente. Veio ensinar acerca da dor da perda de um grande amor? Prova que a resiliência é relativa, fenômeno dinâmico. Não sendo inata depende da circunstância (Yunes, 2003).

\section{Anita - empoderada e menina má que não para? Nem meiga, nem abusada... ${ }^{5}$}

0 consultório está aberto. Anita busca ajuda. Seguiu indicação de sua gestora. Não entende o que está acontecendo, já que sua vida está tão perfeita. Como poderia estar infeliz e ansiosa? Tem tudo o que deseja. Principalmente, a remuneração que sempre sonhou. Anita, mesmo durante a pandemia, trocou de empresa. Tem cargo de executiva de vendas em multinacional na capital. Mudou-se para um apartamento maior, por escolha própria. Separou-se há dois anos e vivia ainda na casa do ex-marido deprimido e falido, mas que ajudava no cuidado das filhas. A separação foi antes de completar 40 anos. Por conta da lipoaspiração, emagreceu 30 quilos. Colocou silicone e fez botox. Diz que sempre foi gordinha, mas gostosa. Só que agora está em outro nível. Mesmo quando não está maquiada, sua boca carnuda e seus supercilios chamam a atenção. A sobrancelha também está modificada. Está se sentindo linda e usa roupas decotadas para mostrar o novo visual. Está sempre bronzeada. Adora se sentir apetitosa e desejada. Pratica kangoo jump e acupuntura com frequência para manter a boa forma.

As duas filhas adolescentes passam o final de semana com o pai biológico, primeiro marido de Anita. Relata que são muito amigos: tornou-se seu confidente e aconselhador de novos relacionamentos. Passa os finais de semana no clube, com amigos ou flertando. Curte o momento de solteirice. Relata que sempre estava com alguém. Teve namorado desde os 16 anos.
Anita tem agilidade na fala. No entanto, as emoções que transparecem nas dinâmicas relacionais são confusas. Agendou avaliação psiquiátrica, porque suspeitava de Transtorno Bipolar. Não entendia o que sentia. Assustava-se consigo mesma quando experimentava tristeza e ansiedade. Acreditava que o normal era estar feliz sempre. Negava o luto pela separação.

Nas sessões, seu discurso traz à tona o enredo dos múltiplos affairs. A relação com as filhas parece paralela a tudo que vivencia. Encara a maternidade como mais uma tarefa na agenda lotada. Apresenta pouca empatia às necessidades afetivas das filhas, embora seja uma mãe provedora de necessidades básicas. Tem se questionado o porquê teve filhas. Aos 20 anos, lembrava claramente que não queria ser mãe. Atualmente, diz que a satisfação maior de vida está na profissão. Sua autonomia profissional e independência financeira contribuem para o crescimento pessoal. Entretanto, emocionalmente, Anita ainda está arraigada a crenças de dependência de inter-relacionamento com a figura masculina. Busca status e poder nas relações de pares. Eexerce competitividade nas relações com outras mulheres. Pela condição física e econômica atual, supõe que outras mulheres a invejam. Acredita-se autossuficiente, de forma narcísica. Recorre pouco às redes de apoio e de suporte social.

Anita é uma mulher contemporânea. Representa bem o ideário coletivo do feminino. Uma vida jovial, interessante e instagramável. De aparência física impecável, busca constantemente a felicidade. A agenda atarefada faz com que se sinta mais importante e especial. É competitiva no mercado de trabalho e no lar, tanto com homens quanto com mulheres. Adora o estilo de vida epicurista, dado aos prazeres à revelia. Considera os outros como parceiros de consumo e componentes ativos da intensificação das volúpias. Os valores intrínsecos dos outros como seres humanos singulares estão quase desaparecendo de vista. A solidariedade está sendo extinguida (Bauman, 2004, p. 96).

Nesse "modelo existencial" não há espaço para a singularidade nem para novas formas saudáveis de subjetividade. Para quem segue esse padrão de ideal de vida, existem riscos maiores de sofrimento psíquico? Embora 0 mal-estar seja inerente a qualquer tipo de civilização, em qualquer estágio evolutivo, parece que sim (Rouanet, 1993, p. 96).

A Psicologia tem muito a contribuir na promoção da saúde mental e do bem-estar frente às múltiplas facetas do mal-estar contemporâneo em mulheres. 0 reconhecimento de que o desamparo está no fundamento da condição humana, constituindo a matéria- prima dos novos laços fraternais em que a solidariedade e a amizade possibilitam a reconstituição dos laços sociais (Birman, 2004, p. 34).

\section{Considerações finais}

A resiliência enquanto competência psicológica constitui fator de proteção à saúde psíquica, pois incita a capacidade de adaptação e flexibilidade diante das adversidades. É processual, dinâmica, associada à capacidade reflexiva. É preciso que a árvore se dobre aos ventos leves e fortes conforme sua capacidade singular de flexibilidade e conforme 0 amparo das raízes de sua rede social (real).

Neste mosaico de mulheres contemporâneas, a personalidade depen-

\footnotetext{
${ }^{5}$ A frase “Empoderada e menina má que não para? Nem meiga, nem abusada..." é um pot-pourri das letras musicais da compositora e cantora Anita. É mulher e ícone das mídias por ser jovem e famosa. Em entrevista exclusiva ao quadro Retratos da Fama, do Jornal Diário Gaúcho, desvendou os segredos do sucesso da música "Show das Poderosas". Considerada uma fábrica de hits, evolui do funk ao pop.
} 
dente aparece de forma mascarada e transloucada por um discurso distorcido de libertação feminista das amarras do mundo privado. A cultura capitalista, de aceleração, de produtivismo, de incertezas perante o futuro e de fragilidade nos laços sociais não é percebida claramente pelas mulheres desse ensaio. Nem, contudo, sua real necessidade de amparo social. Novas Amélias, Leilas Dinis e Anitas sofrem igualmente do mal-estar contemporâneo. De acordo com Bauman (2004) o preço psicológico é alto para quem convive com uma multidão de valores, normas e estilos de vida em competição, sem garantias de certezas.

0 contraponto da força psíquica nessas mulheres não está somente na saída do mundo privado e da sujeição masculina ou da igualdade social no mundo do trabalho, mas sim em sua forma de se tornarem pessoas resilientes. Autoconhecimento, consciência de si e flexibilidade em lidar com as agruras tendem a fortalecer a autoconfiança e a favorecer um ambiente saudável e criativo. A instrumentalização profissional é fundamental ao exercício da atividade clínica com ética.

0 papel da Psicologia, dentre outros, é de propiciar o crescimento saudável do potencial humano, com profissionais atualizados e sensíveis às singularidades, independente do gênero. Eno caso da psique feminina, suscitar uma mulher que se crê autora de sua própria vida. Sem ser vítima do destino. Para ir além da liberdade de pensar o que todos pensam (Rouanet, 1993, p.98).

0 devir de liberdade é um horizonte, como já provocava e inspirava a escritora francesa Simone de Beauvoir, em 0 segundo sexo: "A mulher livre está apenas nascendo (...) Quando for abolida a servidão infinita da mulher, quando ela viver para ela e por ela..." (Beauvoir, 2019, p. 539).

\section{Referências}

American Psychiatric Association. (2014). Diagnostic and Statistical Manual of Mental Disorders, Fifht Edition (DSM-V). 5 ed. Artmed.

Bauman, Z. (2004). Amor líquido: sobre a fragilidade dos laços humanos. Rio de Janeiro: Jorge Zahar Ed.

Berndt, C. (2018). Resiliência: o segredo da força psíquica. Petrópolis: Vozes.

Beauvoir, S. (2019). O segundo sexo: a experiência vivida. 5.ed. Rio de Janeiro: Nova Fronteira.

Birman, J. (2004). Fraternidades, seus destinos e impasses. In: Peixoto, C. A. Jr. Formas de subjetivação. Rio de Janeiro: Contracapa Livraria.

Borges, C. S. (2020). Resiliência psicológica: (im) possibilidades de avaliação em mulheres adultas no contexto do mal-estar contemporâneo. (Trabalho de conclusão de curso). Instituto de Pós-Graduação do RS - IPOG, Porto Alegre, RS, Brasil.

Debord, G. (1967). Sociedade do espetáculo. Recuperado de: https://www. marxists.org/portugues/debord/1967/11/sociedade.pdf

Goldenberg, M. (2008). Toda mulher é meio Leila Diniz. Rio de Janeiro: BestBolso.

Han Byung-Chu. (2017). Sociedade do Cansaço. Petrópolis: Editora Vozes.

Reppold, C. T. (2012). Avaliação da resiliência: controvérsia em torno do uso das escalas. Psicologia: Reflexão e Critica. vol. 25. Porto Alegre.

Rouanet, P. S. (1993). Mal-estar na Modernidade. São Paulo: Companhia das Letras.

Shainess, N. (1984). A masoquista se safa. In: 0 doce sofrimento. São Paulo: Melhoramentos.

Sistema de Avaliação de Testes Psicológicos (SATEPSI). Recuperado de: http:// satepsi.cfp.org.br/
Yunes, Maria Angela Mattar. (2003). Psicologia positiva e resiliência: o foco no indivíduo e na família. Psicologia em Estudo, 8, 75-84. https://doi. org/10.1590/S1413-73722003000300010

Yunes, M.A.M. \& Symanski, H. (2001). Resiliência: noção, conceitos afins e considerações críticas. In: Tavares, J. (Org.), Resiliência e educação (pp. 13-42). São Paulo: Cortez. 